\title{
EVALUATION OF ANTIBACTERIAL, MECHANICAL, AND COMFORT PROPERTIES OF WOVEN FABRICS CONSIST OF COTTON, BAMBOO, AND SILVER FIBERS
}

\author{
Ayşe Ebru TAYYAR ${ }^{1}$, Gamze D.TETiK ${ }^{2}$, Emel ABAK ${ }^{3}$ \\ ${ }^{I}$ Uşak University, Faculty of Engineering, Department of Textile Engineering,

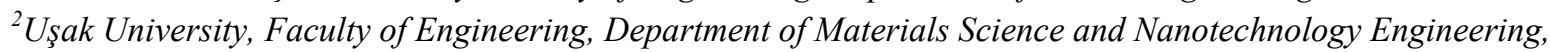 \\ ${ }^{3}$ Ușak University, Graduate School of Natural and Applied Sciences, Department of Textile Engineering
}

Received: 28.06.2018

Accepted: 20.11 .2018

\begin{abstract}
In this study, experimental and statistical evaluation of antibacterial, mechanical, and comfort properties of woven fabrics consisting of cotton, bamboo and silver yarns were presented. For the purpose of the study; cotton-bamboo and cotton-silver blended fabrics were produced, mechanical properties (such as tensile strength and tear strength) were investigated, antibacterial activities were determined, and thermal comfort properties (such as thermal conductivity, thermal absorption, thermal resistance, air permeability, water vapor permeability, and water vapor resistance) were measured. Statistical evaluations were performed by one way ANOVA and Tukey HSD and Tamhane's T2 test methods. According to the outputs of the research, the mechanical and comfort properties can be improved and the antibacterial activities can be obtained of shirting and bedding fabrics by differing weft yarn type and density.
\end{abstract}

Keywords: Woven fabrics, antibacterial activity, comfort properties, mechanical properties, cotton, bamboo, silver

Corresponding Author: Ayșe Ebru TAYYAR ayseebru.tayyar@usak.edu.tr / DOI: 10.32710/tekstilvekonfeksiyon.493098

\section{INTRODUCTION}

In recent years, the properties expected from textile products have increased, as well as in all consumer products. People have begun to prefer fabrics and garments possessing multiple properties instead of fabrics with only one improved feature. In this context, researchers have begun to study on fabrics that meet demands of consumers for different purposes at once. Various raw materials, types of yarns, weaves or finishing techniques have been applied for the production and evaluation of multi-property fabrics.

Mechanical properties are mostly the main properties in characterization of fabrics depending on last usage area. Zupin and Dimitrovski studied the mechanical properties of woven fabrics produced by using cotton, soybean protein fibers, polylactic acid and bamboo in weft and cotton in warp. They found that pure cotton fabrics were the mechanically strongest ones and the fabrics with bamboo were the weakest ones (1). Mishra et al. investigated some physical properties of cotton, viscose rayon, bamboo and cotton/bamboo blended woven fabrics. According to their results, extensibility of viscose rayon and bamboo fabrics were higher than cotton/bamboo blend and cotton fabrics. Also the tensile energy results were higher for bamboo and viscose rayon than for cotton (2).
Comfort properties are also evaluated and tried to be improved for obtaining multi-property fabrics. Comfort is an important quality criterion for textile products that defines pleasure (3). In the literature, one can encounter lots of studies about thermal comfort properties of fabrics. Although there are lots of studies evaluating thermal comfort properties of knitted fabrics (2-6), there are limited studies about the evaluation of woven ones.

The effect of bamboo and cotton fiber blend ratio on thermal comfort properties of woven fabrics were evaluated by Chidambaram and Govindan (7). They have observed that with the increase in bamboo content, more air and water permeable fabrics having lower thermal resistances were obtained. The effects of weft fiber type (cross section, different types of synthetic fibers) were also the other parameters evaluated by researchers. Kakvan et al. examined the thermal comfort properties of woven fabrics composing of Kermel, cotton, and nylon yarns (8). They stated that they obtained the desirable comfort properties with the fiber blend ration of $50 / 10 / 40$ cotton/Nylon $® /$

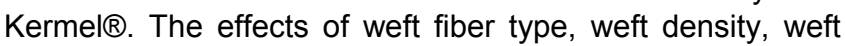
yarn count, weave pattern were the other parameters evaluated by Erenler and Oğulata (9). They designed artificial neural network models for prediction of comfort 
properties of woven fabrics. They obtained high regression values and stated that the air and water vapor permeability of fabrics could be successfully predicted before manufacture. Özdemir studied with different weaves and polyester/cotton blends in his woven fabrics (10). He stated that the effect of fiber type on thermal resistances of fabrics was significant. $\mathrm{He}$ also indicated that the increasing polyester ratio had made the fabric more suitable for winter as the thermal resistances were getting higher. His other result was about weave patterns. He stated that twill weaves were more suitable for winter and diced weaves were for summer according to the water vapor resistances of fabrics. Uzun assessed the thermal comfort properties of cotton/polyester blended woven fabrics according to the ultrasonic and traditional washing methods (11). The thermal absorption values of fabrics have increased by the ultrasonic washing method which wears the fabric less than traditional washing method.

Antimicrobial activities of fabrics are also the other important properties examined in detail in the literature, especially for biomaterial applications. However, nowadays antimicrobial activity for garments has also become important. Effects of different fiber types included in fabric structure, a diverse set of antimicrobial agents (such as plant extracts, active agents that exhibit intrinsic antimicrobial activity, etc.) coated on fabrics, and various ions (such as silver, copper, etc.) loaded on yarns or fabrics were investigated.

Zinc (12, 13), magnesium (14), copper (15), and silver (16, 17) based nanoparticles or agents were used for the improvement of the antibacterial activities of textiles by some researchers. Uzun evaluated the antibacterial effect of cotton, organic cotton and bamboo woven fabrics treated with alginate and copper ions (15). He showed that there was a considerable increase in the antibacterial activity of cotton and organic cotton woven fabrics treated with alginate and copper ions, while the treated bamboo had no activity. He stated that the natural antimicrobial properties of bamboo might be lost after ion treatment. Saraswathi et al. studied woven fabrics of cotton and silk loaded with microcapsules containing antimicrobial herbal extract mixture by pad dry method (18). They obtained effective results by this herbal extract mixture. Subramanian et al. revealed the antibacterial effect of copper oxide films sputtered on woven fabrics in their study (19). Another study was carried out by Lee and Jeong to investigate the antibacterial effect of nanosized silver coating on woven cotton and nonwoven polyester fabrics (20). A 20 ppm concentration of silver nanoparticles was the most efficient woven fabric coating. Effective antibacterial fabric results were obtained in another study including cotton plain weave fabrics coated with copper oxide nanoparticles (21). Antibacterial activities of silver loaded cellulosic fiber and cotton blends were also studied. It was emphasized that silver content had a considerable effect on the antibacterial activity of fabrics (22). As it can be seen in the literature loading antibacterial agents on fabrics by some finishing techniques or adding antibacterial fibers to the fabric structures have attracted much attention for many years.

Since the demands of people from textile products are no longer limited to only one unique property, the studies aiming the evaluation of fabrics by a versatile way have been appreciated. The originality of the work comes from the assessment of both antibacterial activity, mechanical properties, and comfort properties of fabrics including cotton (CO), bamboo (BAM), and cotton/silver (CO/Ag) yarns in order to design fabrics fulfill people requirements. To the best of our knowledge there is no other study examining all of the properties mentioned for woven fabrics composing of $\mathrm{CO}$, BAM, and CO/Ag yarns.

\section{MATERIALS AND METHODS}

\subsection{Materials}

All yarns were purchased from a local company. Properties of yarns are given in Table 1. All yarn samples were conditioned at standard atmospheric conditions before the tests. The linear densities of yarns were measured by ProSer automatic wrap reel. The twists of yarns were measured by Mesdan Lab electronic twist tester using "untwist/retwist" method for single yarns. All yarns were tested by Uster Tensorapid constant rate of elongation tensile tester. For the ease of expression, yarns types were coded as shown in Table 1.

The yarns given in Table 1 were used as weft yarns and the warp yarn was selected as $100 \%$ CO with a linear density of $\mathrm{Ne} \mathrm{30/1}$ for all types of fabrics.

The weaving process parameters were as follows: machine speed was $525 \mathrm{rpm}$, reed width was $193 \mathrm{~cm}$, raw fabric width was $185 \mathrm{~cm}$, ends of warp were 8106, 14 dents $/ \mathrm{cm}$ reed with 3 threads/dent. These fabrics were considered as shirting or bedding fabrics, so the weaves were chosen as twill (2/1) and 3 different weft densities were chosen as 25 , 29 , and 34 picks/cm (ppc). The warp densities of the fabrics were kept constant at 42 ends/cm (epc). The fabrics were coded as CO-34, CO-29, CO-25, BAM-34, BAM-29, BAM25, CO/Ag-34, CO/Ag-29, and CO/Ag-25 according to the weft materials and densities of fabrics.

\subsection{Methods}

All fabric samples were conditioned at standard atmospheric conditions before the tests.. First of all basis weights of fabrics were determined according to ISO 3801 standard and given in Table 2. For detailed characterization of fabrics some mechanical and physical tests have been conducted. Tensile strength and elongation for both warp and weft directions were measured according to ISO 13934-1 by UTest Tensile Tester in Usak University Scientific Analysis and Technological Application and Research Center. Tear strength for both directions were measured according to single tear method (ISO 13937-2). Air permeability was measured by Prowhite Airtester II instrument according to the ISO 9237 at a pressure of $100 \mathrm{~Pa}$. Thermal conductivity, thermal resistance, and thermal absorptivity values were measured by Alambeta instrument according to ISO 11092. Water vapor permeability of fabrics were determined by Permetest instrument (ISO 11092). After these structural and performance investigations, antibacterial activity tests were performed on the fabric samples that have the highest densities (34 picks/cm) in $\mathrm{CO}, \mathrm{CO} / \mathrm{Ag}$, and BAM after repeated washings $(0,1$, and 10$)$ according to AATCC test 
method 100. Gram positive S.aureus (ATCC 6538) and gram negative E.coli (ATCC 11230) were chosen as test bacteria. Fabrics were coded as CO-0, CO-1, CO-10, CO/Ag-0, CO/Ag-1, CO/Ag-10, BAM-0, BAM-1, and BAM-10 according to wash repeats. Also, fabrics were kept at a temperature of $121^{\circ} \mathrm{C}$ and at a pressure of $1 \mathrm{~atm}$ for $15 \mathrm{~min}$ in an autoclave for sterilization before the antibacterial activity test.

All the data was analyzed by IBM SPSS Statistics-Version 23 package program. The one-way analysis of variances tests were performed for the evaluation of effects of chosen parameters on the properties of yarns and fabrics manufactured by these yarns. Homogeneities of variances were tested with Levene's test. The Tukey HSD (for $p>0.05$ ) or Tamhane's T2 (for $p<0.05$ ) post hoc tests were used to determine the significant differences according to the homogeneity of variances. The confidence interval was chosen as $95 \%$ and thus $p$ values $<0.05$ were considered as significant.

\section{RESULTS AND DISCUSSIONS}

\subsection{Antibacterial Activities of Yarns}

Antibacterial activities of three yarns against S.aureus and E.coli are given in Figure 1. For all the yarns tested against
S. aureus and E.coli, the antibacterial effects were observed by only CO/Ag yarns. The CO/Ag yarns exhibited $99.99 \%$ antibacterial effect in $24 \mathrm{~h}$ both against S.aureus and E.coli. BAM yarns exhibited $2.43 \%$ antibacterial effect in $24 \mathrm{~h}$ only for gram positive S.aureus.

The effect of silver ions in the yarn structure is explained as attaching cell surface of bacteria, interacting with enzymes of bacteria and finally inactivation of cell activity $(23,24)$. The antibacterial effect of BAM yarns were originated from the intrinsic properties of the BAM fiber. BAM fibers contain in themselves a unique agent defined as "bamboo chinone". By means of this peerless agent bamboo fiber serves as a bactericidal material. Here we observed a very low antibacterial activity against S.aureus with BAM yarns.

\subsection{Mechanical Properties of Fabrics}

The mechanical property results of total 9 fabrics (for three types of yarns and for three values of weft densities) are given in Figure 2 and Figure 3.

For the statistical evaluation of mechanical (and also thermal comfort) properties of fabrics, multiple comparison test were performed between fabrics consisting of different yarns while the ppc values kept constant and likewise between the fabrics possessing different ppc values while the yarns of fabrics kept constant.

Table 1. Properties and codes of yarns

\begin{tabular}{|c|c|c|c|c|c|c|c|c|c|}
\hline \multirow{2}{*}{$\begin{array}{l}\text { Yarn } \\
\text { Code }\end{array}$} & \multirow[t]{2}{*}{ Yarn Type } & \multicolumn{2}{|c|}{ Linear Density } & \multicolumn{2}{|c|}{ Twist } & \multicolumn{2}{|c|}{ Twist multiplier } & \multirow{2}{*}{$\frac{\text { Rkm }}{\text { Kgf }^{\star} \mathrm{Nm}}$} & \multirow{2}{*}{$\begin{array}{c}\text { Elong. } \\
\%\end{array}$} \\
\hline & & $\mathrm{Ne}$ & $\mathrm{Nm}$ & $(T / ")$ & $\mathrm{T} / \mathrm{m}$ & $\alpha_{e}$ & $\alpha_{m}$ & & \\
\hline CO & $100 \%$ Cotton & $30 / 1$ & $50.8 / 1$ & $22.17 \pm 0.66$ & $873 \pm 26$ & 4.05 & 122.48 & 13.80 & 3.86 \\
\hline CO/Ag & 90/10 \% Cotton/Silver & $30 / 1$ & $50.8 / 1$ & $23.61 \pm 0.79$ & $930 \pm 31$ & 4.31 & 130.43 & 14.68 & 5.73 \\
\hline BAM & $100 \%$ Bamboo & $30 / 1$ & $50.8 / 1$ & $20.47 \pm 0.94$ & $806 \pm 37$ & 3.74 & 113.08 & 17.02 & 14.19 \\
\hline
\end{tabular}

Table 2. Weight and thickness values of fabrics

\begin{tabular}{|l|c|c|l|c|c|l|c|c|}
\hline $\begin{array}{l}\text { Fabric } \\
\text { codes }\end{array}$ & $\begin{array}{c}\text { Weight } \\
\mathbf{( g / m 2 )}\end{array}$ & $\begin{array}{c}\text { Thickness } \\
\mathbf{( m m})\end{array}$ & $\begin{array}{l}\text { Fabric } \\
\text { codes }\end{array}$ & $\begin{array}{c}\text { Weight } \\
\mathbf{( g / m 2})\end{array}$ & $\begin{array}{c}\text { Thickness } \\
\mathbf{( m m})\end{array}$ & $\begin{array}{l}\text { Fabric } \\
\text { codes }\end{array}$ & $\begin{array}{c}\text { Weight } \\
\mathbf{( g / m 2 )}\end{array}$ & $\begin{array}{c}\text { Thickness } \\
\mathbf{( m m})\end{array}$ \\
\hline CO-34 & $169.9 \pm 1.4$ & $0.49 \pm 0.01$ & CO/Ag-34 & $174.0 \pm 0.9$ & $0.55 \pm 0.01$ & BAM-34 & $172.1 \pm 0.6$ & $0.48 \pm 0.01$ \\
\hline CO-29 & $157.5 \pm 0.9$ & $0.51 \pm 0.02$ & CO/Ag-29 & $160.7 \pm 0.8$ & $0.51 \pm 0.02$ & BAM-29 & $160.7 \pm 1.6$ & $0.46 \pm 0.01$ \\
\hline CO-25 & $147.3 \pm 0.8$ & $0.51 \pm 0.01$ & CO/Ag-25 & $151.4 \pm 0.7$ & $0.48 \pm 0.01$ & BAM-25 & $150.8 \pm 0.6$ & $0.49 \pm 0.01$ \\
\hline
\end{tabular}

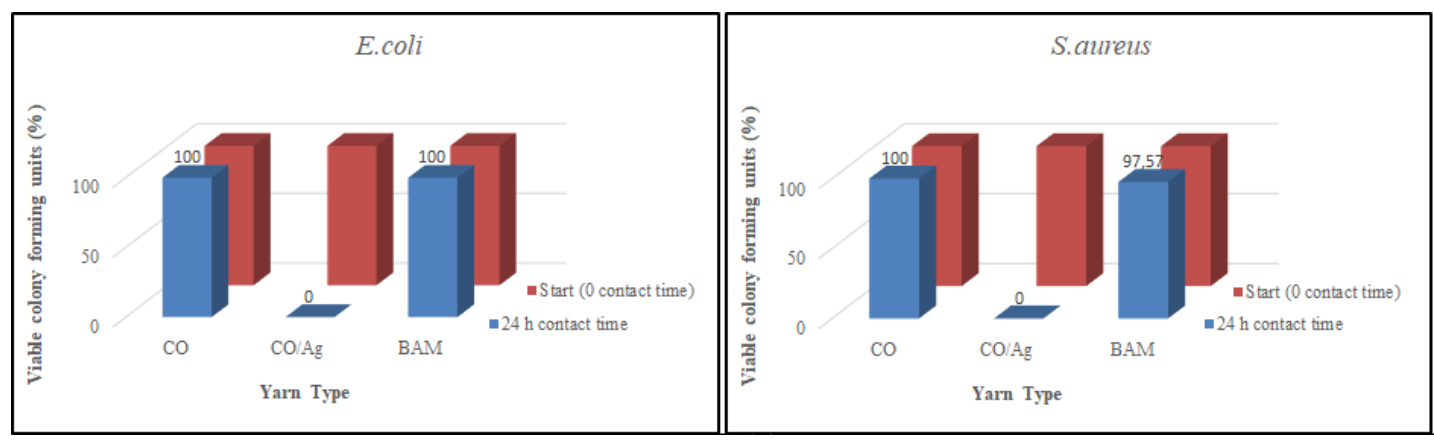

Figure 1. Antibacterial properties of yarns 
BAM fabric that has the highest density also has the maximum tenacity values in both directions. For the tenacity values in warp and weft directions the order of fabrics is: $\mathrm{BAM}>\mathrm{CO} / \mathrm{Ag}>\mathrm{CO}$ as the order of tenacity values of yarns. But when we considered the statistical significance between these fabrics we saw that, only CO-29 and CO/Ag-29, CO29 and BAM-29 fabrics were statistically different from each other for tensile strength in warp direction and $p$ values were 0.033 and 0.029 , respectively. The same fabrics were also different form each other at a weft density of 25 in terms of tensile strength in weft direction $p$ values were 0.027 and 0.012 , respectively. The minority in the significantly different sample numbers could be explained by the fact that the warp yarn is $100 \%$ CO for all fabric types. However when yarns forming the fabrics were same, the ppc values made a significant impact on weft tensile strength of fabrics. For all the fabrics multiply compared, $p$ values were $<0.05$. The weft tensile strength showed a tendency to increase with increasing ppc as shown in Figure 2.

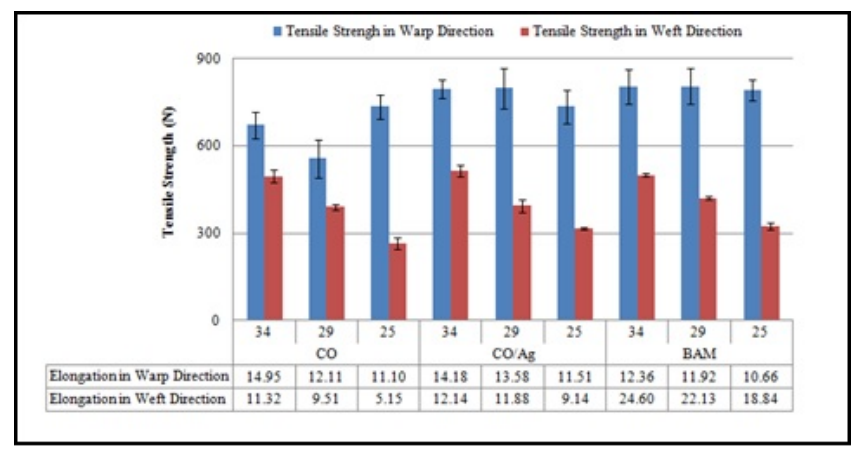

Figure 2. Tensile strength and elongation values of fabrics

Tear strength values in weft direction are higher than the values in warp direction for all fabrics except BAM (Figure 3). Tear strength values of fabrics were especially affected by yarn strength. That is why the tear strength values in warp direction in BAM fabrics are higher.

The tear strength values in warp direction exhibit a significant difference between the samples of CO-BAM and CO/Ag-BAM with $25 \mathrm{ppc}$ and $29 \mathrm{ppc}$ (all of the four $\mathrm{p}$ values were $<0.05$ ). When the yarns of fabrics were the same, BAM-34 fabric exhibited significant difference from the other BAM samples $(p<0.05)$. Almost all different yarn fabrics were significantly different from each other in terms of weft tear strength $(p<0.05)$. If the ppc values are considered, only CO-34 exhibited significant difference from CO-29 and 25 in terms of weft tear strength.

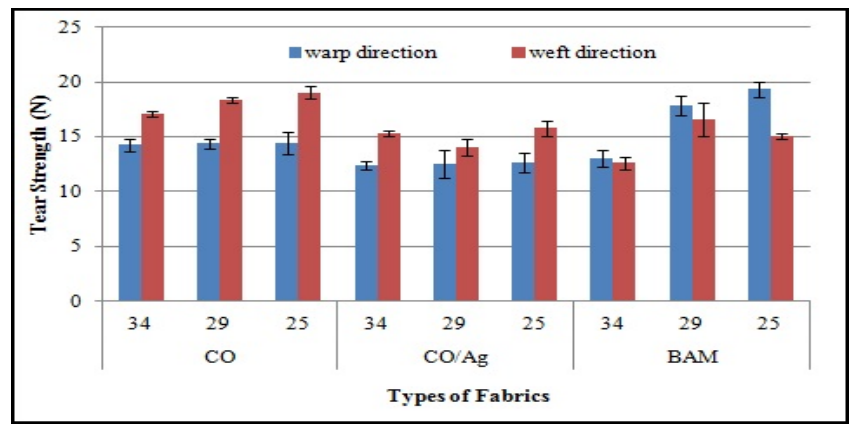

Figure 3. Tear strength values of fabrics

\subsection{Comfort Properties of Fabrics}

Thermal conductivity, thermal absorption, thermal resistance, air permeability, water vapor permeability, and water vapor resistance were taken into consideration while mentioning from fabric comfort properties.

Thermal conductivities of fabrics are given in Figure 4. Although the fibers of weft yarns are different, the thermal conductivity values of the fabrics tested were not significantly different from each other $(p>0.05)$ (due to the same fabric weave and yarn linear density. Thermal conductivity value of BAM-34 fabric was significantly lower than that of BAM-29 fabric $(p=0.048)$. Since the fiber type is a major factor affecting thermal conductivity, this decrease can be attributed to the increase in the ratio of BAM yarns in the BAM-34 fabric structure as stated in Majumbar et al.'s study (25).

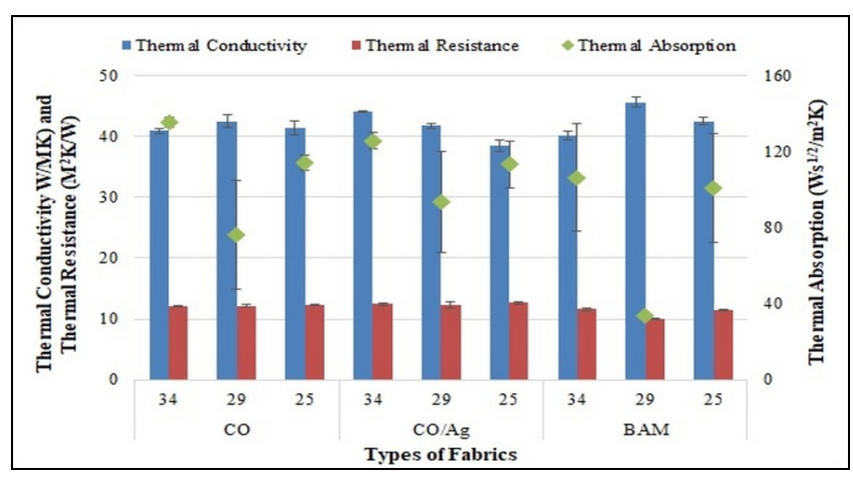

Figure 4. Thermal conductivity, absorption, and resistance values of fabrics

The thermal absorption values of fabrics are given in Figure 4. Thermal absorption values of fabrics tested did not differ from each other $(p>0.05)$ since the variations were so high as seen in Figure 4. However, there was a tendency to decrease in thermal absorptions with lower weft densities. Since, the less the fiber amount is, the less thermal absorption it is.

The thermal resistances of fabrics are given in Figure 4. Since the thermal resistances of fabrics are related with thermal conductivity and thickness, only the significant differences were observed between CO-25 and BAM-25 fabrics $(p=0.009), C O-29$ and BAM-29 fabrics $(p=0.004)$, and within BAM fabrics with $25 \mathrm{ppc}$ and $29 \mathrm{ppc}(\mathrm{p}=0.004)$. It was obvious from the results that the differences were related to the BAM contents. The thickness values of BAM25 and 29 fabrics were lower than CO-25 and 29 fabrics, respectively. This led BAM fabrics to possess lower thermal resistances.

The air permeability values of fabrics are given in Figure 5 . The fabrics with higher densities have the lowest air permeability value and vice versa as expected. The air permeability of fabrics with different weft densities are different statistically $(p<0.05)$. The porosity, cover factor and compactness of the fabric structure determined by weft yarn densities affected this phenomenon. An increase in ppc value caused lower porosity and higher compactness resulted in lower air permeability values. Also the air 
permeability values of BAM-34 fabrics were the highest among the CO/Ag-34 and CO-34 fabrics $(p<0.05)$.

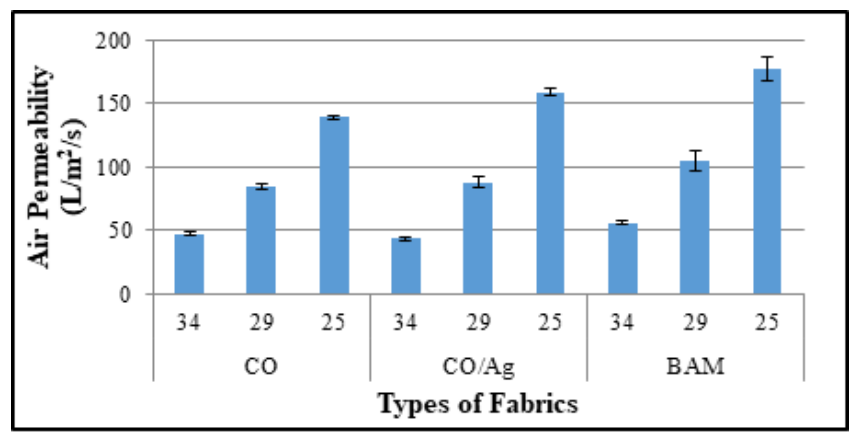

Figure 5. Air permeability values of fabrics

Water vapor permeability and water vapor resistances are the other parameters that are taken into consideration while examining fabric comfort properties, since not only heat transfer but also moisture transfer from the skin is also a significant property in providing comfort. Water vapor permeability of fabrics are related to tightness of fabrics (density and weave type), fiber types and yarn types used $(26,27)$. In this study it was observed that fiber types did not exhibit any meaningful differences in terms of water vapor permeability $(p>0.05)$ but the densities of the fabrics did $(p<0.05)$. The lower the density were, the higher the water vapor permeability values were observed (Figure 6). In a similar manner water vapor resistance was not different in terms of fiber types used, but it was showing a tendency to decrease by the decreasing ppc value (Figure 6).

\subsection{Antimicrobial Activities of Fabrics}

When the antibacterial activities of fabrics were considered, it was observed that only the two fabric samples among all 9 tested exhibited antibacterial activities against both gram positive S.aureus and gram negative E.coli: $\mathrm{CO} / \mathrm{Ag}-10$ and BAM-10 samples (Figure 7). Figure 7 (i-I) show uninhibited S.aureus and E.coli bacteria colonies tested by $\mathrm{CO}-10$ samples.

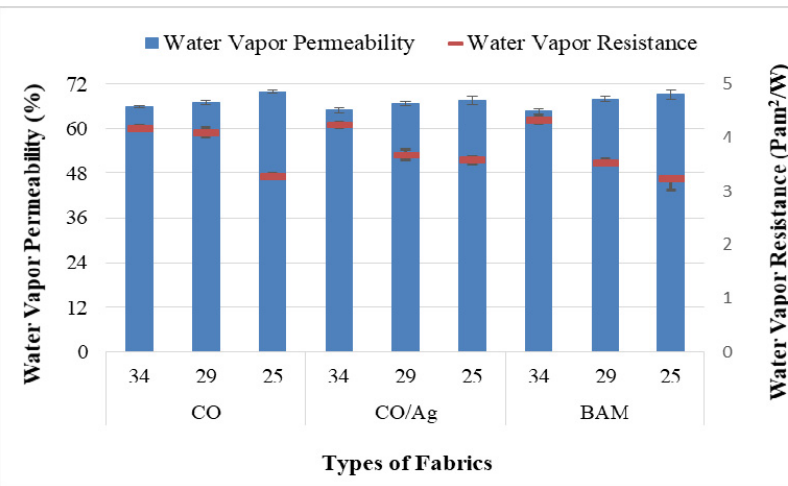

Figure 6. Water vapor permeability and resistance values of fabrics

As it was stressed in the literature that bamboo had antimicrobial effect, it was also emphasized that this effect might not arise in all cases. Moisture regain and hygroscopicity were the two main parameters that reveal antimicrobial activities. If an extraction was applied and hygroscopicity of the bamboo fiber was changed, extractives that contain antibacterial agent came into light and changed the chemical composition and $\mathrm{pH}$ of the fiber, also makes it more antibacterial (28). In this context, it can be said that multiple washing cycles acted as extraction methods and made the fiber more antibacterial in BAM-10 samples.

The effective antibacterial activity obtained by $\mathrm{CO} / \mathrm{Ag}-10$ fabric samples can be attributed to the release of much more $\mathrm{Ag}+$ ions to the extract medium due to the repeated washings. ${ }^{36}$ Then $\mathrm{Ag}+$ ions released to medium attack the cell membrane of bacteria or penetrate it to inhibit viability.

\section{CONCLUSIONS}

In this study, experimental and statistical evaluation of antibacterial, mechanical, and comfort properties of woven fabrics consisting of cotton, bamboo and silver yarns were presented. This study revealed that mechanical, comfort and antibacterial properties of fabrics can be enhanced by using different yarns in weft. When yarns were considered, it was observed that only $\mathrm{CO} / \mathrm{Ag}$ blended yarns exhibited perfect antibacterial activity against gram positive and gram negative bacteria. Only fabrics that consist of BAM yarns and $\mathrm{CO} / \mathrm{Ag}$ blended yarns washed 10 times exhibited perfect antibacterial activity against S.aureus and E.coli. This is why the release of $\mathrm{Ag}+$ ions and antibacterial agents to the medium increased.

Keeping fabric weave and yarn linear density constant caused some properties to be insignificantly different while tensile strength of the fabrics showed a tendency to increase with increasing weft density. The increase in the ratio of BAM yarns made the fabrics less thermally conductive. Also lower thermal resistance values were observed with BAM yarn content. Air permeability, water vapor permeability showed a tendency to increase with decreasing weft yarn density, and the opposite was valid for water vapor resistance.

According to the overall results fabrics produced within the scope of the study are suitable for shirting or bedding. For further examination of all these properties, ratios of silver and bamboo yarns in the fabric structure may be increased, another antibacterial activity test method may be performed (like disc diffusion method).

\section{Funding}

This work was supported by the Uşak University Scientific Research Coordination Unit under Grant No. 2014/MF004. 


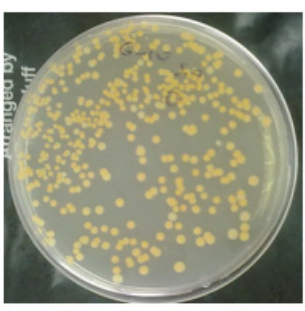

(a)

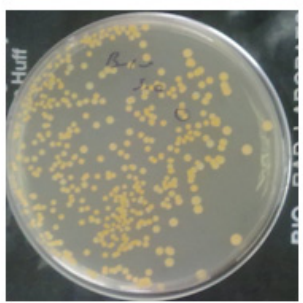

(e)

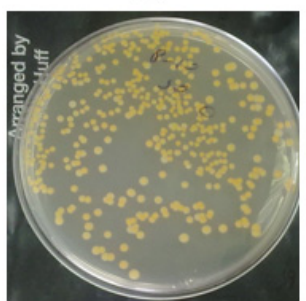

(i)

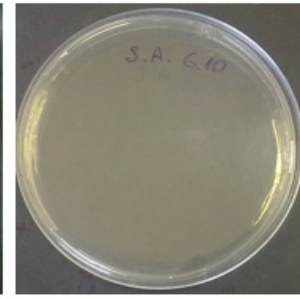

(b)

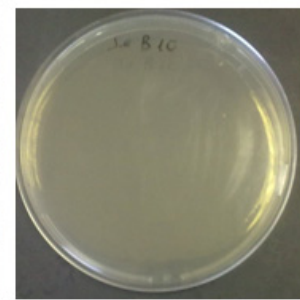

(f)

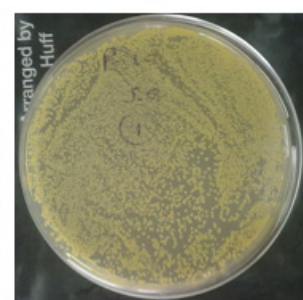

(j)

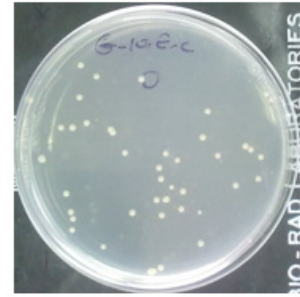

(c)

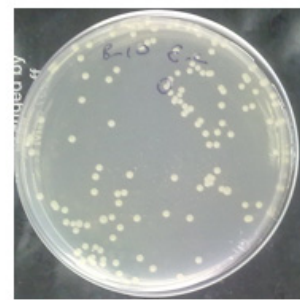

(g)

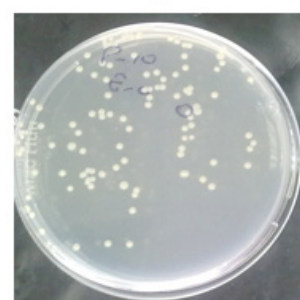

(k)

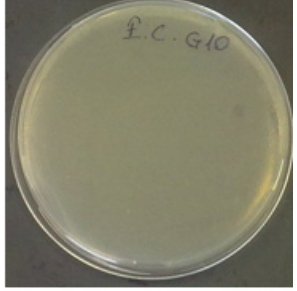

(d)

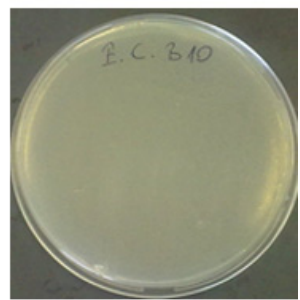

(h)

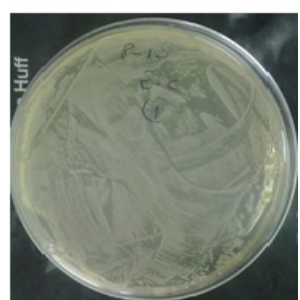

(I)

Figure 7. Photos of uninhibited and inhibited (a, b) S.aureus colonies by CO/Ag-10 samples at 0 and $24 \mathrm{~h}$ contact times, respectively, (c,d) E.coli colonies by CO/Ag-10 samples at 0 and $24 \mathrm{~h}$ contact times, respectively, (e,f) S.aureus colonies by BAM-10 samples at 0 and $24 \mathrm{~h}$ contact times, respectively, ( $\mathrm{g}, \mathrm{h})$ E.coli colonies by BAM-10 samples at 0 and $24 \mathrm{~h}$ contact times, respectively, (i,j) S. aureus colonies by CO- 10 samples at 0 and $24 \mathrm{~h}$ contact times, respectively, (k,l) E.coli colonies by CO-10 samples at 0 and 24 h contact times, respectively.

\section{REFERENCES}

1. Zupin Z. and Dimitrovski K., 2010, "Mechanical Properties of Fabrics Made from Cotton and Biodegradable Yarns Bamboo, SPF, PLA in weft", Woven Fabric Engineering, Polono Dobnik Dubrovski (Ed.), IntechOpen, pp: 25-46.

2. Mishra R., Behera BK., Pal BP., 2012, "Novelty of Bamboo Fabric”, The Journal of The Textile Institute, Vol: 103(3), pp: 320-329.

3. Celep G., 2015, "Novel Study of Developing Models of Comfort Properties of Textile Products Made of Hollow Yarns", PhD Thesis, Usak University Graduate School of Natural and Applied Sciences, 155p.

4. Erdumlu N. and Sarıçam C, 2016, "Investigating the effect of some fabric parameters on the thermal comfort properties of flat knitted acrylic fabrics for winter wear", Textile Research Journal, Vol: 87, pp: 1349-1359.

5. Özgen B. and Altaş S, 2014, "The Investigation of Thermal Comfort, Moisture Management and Handle Properties of Knitted Fabrics Made of Various Fibres, Tekstil ve Konfeksiyon, Vol: 24(3), pp 272-278.

6. Oglakcioglu N., Celik P., Ute TB., Marmarali A., Kadioglu H., 2009, "Thermal Comfort Properties of Angora Rabbit/Cotton Fiber Blended Knitted Fabrics", Textile Research Journal, Vol: 79, pp: 888-894.

7. Chidambaram P. and Govindan R., 2012, "Influence of Blend Ratio on Thermal Properties of Bamboo/Cotton Blended Woven Fabrics", Silpakorn U Science \& Tech Journal, Vol: 6, pp: 49-55.

8. Kakvan A., Najar SS., Psikuta A., 2015, "Study on effect of blend ratio on thermal comfort properties of cotton/nylon-blended fabrics with high-performance Kermel fibre", The Journal of The Textile Institute, Vol: 106, pp: 674-682.

9. Erenler A. and Oğulata R., 2015, "Investigation and Prediction of Chosen Comfort Properties on Woven Fabrics for Clothing, TEkstil ve Konfeksiyon, Vol: 25(2), pp125-134.

10. Özdemir H., 2017, "Thermal Comfort Properties of Clothing Fabrics Woven With Polyester/Cotton Blend Yarns", Autex Research Journal, Vol: 17, pp: 135141.

11. Uzun M., 2012, "An Investigation of the Effects of Ultrasonic and Traditional Washing Methods on Thermal Comfort Properties of Woven Fabrics", Tekstil ve Mühendis, Vol: 19, pp: 1-6.

12. Shaker K., Ashraf M., Jabbar M., Shahid S., Nawab Y., Zia J, Rehman A., 2016, "Bioactive woven flax-based composites: Development and characterization", Journal of Industrial Textiles, Vol: 46, pp: 549-561.

13. Dastjerdi R., Mojtahedi MRM., Shoshtari AM., Khosroshahi A., Moayed AJ., 2009, "Fiber to Fabric Processability of Silver/Zinc-loaded Nanocomposite Yarns", Textile Research Journal, Vol: 79, pp: 1099-1107.

14. Zhu Y., Wang Y., Sha L., Zhao J., 2017, "Preparation of antimicrobial fabric using magnesium-based PET masterbatch", Journal of Applied Surface Science, Vol: 425, pp: 1101-1110. 
15. Uzun M., 2013, "Interaction of Alginate/Copper System on Cotton and Bamboo Fabrics: The Effect on Antimicrobial Activity and Thermophysiological Comfort Properties", Materials Science (Medžiagotyra), Vol: 19, pp: 301-308.

16. Pollini M, Russo M, Licciulli A, Sannino A., Maffezzoli A., 2009, "Characterization of antibacterial silver coated yarns", Journal of Materials Science: Materials in Medicine, Vol: 20, pp:2361-2366.

17. Damerchely R., Yazdanshenas ME., Rashidi AS., Khajavi R., 2011, "Morphology and mechanical properties of antibacterial nylon 6/nano-silver nanocomposite multifilament yarns", Textile Research Journal, Vol: 81, pp: 1694-1701.

18. Saraswathi R., Krishnan PN., Dilip C., 2010, “Antimicrobial Activity of Cotton and Silk With Herbal Extract By Micro Encapsulation”, Asian Pacific Journal of Tropical Medicine, Vol: 3, pp: 128-132.

19. Subramanian B., Priya KA., Rajan ST., Dhandapani P., Jayachandran M., 2014, "Antimicrobial activity of sputtered nanocrystalline CuO impregnated fabrics", Materials Letters, Vol: 128, pp: 1-4.

20. Lee HJ. and Jeong SH., 2005, "Bacteriostasis and Skin Innoxiousness of Nanosize Silver Colloids on Textile Fabrics", Textile Research Journal, Vol: 75, pp: 551-556.

21. Anita S., Ramachandran T., Rajendran R., Koushik CV., Mahalakshmi M., 2011, "A study of the antimicrobial property of encapsulated copper oxide nanoparticles on cotton fabric", Textile Research Journal, Vol: 81, pp: 1081-1088.

22. Üreyen M., Gök Ö., Ateş M., Günkaya G., Süzer Ş., 2010, "Evaluation of Silver Content and Antibacterial Activities of Silver Loaded Fiber/Cotton Blended Textile Fabrics, Tekstil ve Konfeksiyon, Vol: 20(2), pp: 137-144.

23. Morones JR, Elechiguerra JL, Camacho A, Holt K., Kouri JB., Ramirez JT, Yacaman MJ., 2005, "The bactericidal effect of silver nanoparticles", Nanotechnology, Vol: 16, pp: 2346-53.

24. Palamutcu S, Keskin R, Devrent N, Keskin R., Hasçelik B., 2008, "Bazı Antimikrobiyal Maddelerin \%100 Pamuklu Kumaşlar Üzerindeki Mikrobiyolojik Etkinliği ve Kumaş Parametreleri Üzerindeki Etkilerinin Araştırılması”, Database of TÜBITAK Supported Projects, Project Report, Project Number: $106 \mathrm{M} 338$.

25. Majumdar A., Mukhopadhyay S., Yadav R., 2010, "Thermal properties of knitted fabrics made from cotton and regenerated bamboo cellulosic fibres", International Journal of Thermal Sciences, Vol: 49, pp: 2042-2048.

26. Das A. and Ishtiaque SM., 2004, "Comfort Characteristics of Fabrics Containing Twist-less and Holow Fibrous Assemblies in Weft", Journal of Textile and Apparel, Technology and Management, Vol: 3, pp: 1-7.

27. Behera BK., Ishtiaque SM., Chand S., 1997, "Comfort Properties of Fabrics Woven from Ring-, Rotor-, and Friction-spun Yarns", The Journal of The Textile Institute, Vol: 88, pp: 255-264.

28. Xi LX. and Qin DC., 2012, "The Antibacterial Performance of Natural Bamboo Fiber and Its Influencing Factors", In Proceedings of the 55th International Convention of Society of Wood Science and Technology, 27-31 August, Beijing, China, pp:1-8.

29. Lorenz C, Windler L, Goetz N, Lehmann RP., Schuppler M., Hungerbühler K., Heuberger M., Nowack B., 2012, "Characterization of silver release from commercially available functional (nano)textiles", Chemosphere, Vol: 89, pp: 817-824. 